\title{
MULTI-OBJECTIVE CONTROL DESIGN FOR STOCHASTIC LARGE-SCALE SYSTEMS BASED ON LMI APPROACH AND SLIDING MODE CONTROL CONCEPT
}

Koan-Yuh Chang

Department of Electronic Engineering, Chienkuo Technology University, Changhua 500, Taiwan, R.O.C.

Wen-Jer Chang

Department of Marine Engineering, National Taiwan Ocean University, Keelung 202, Taiwan, R. O. C., wjchang@mail.ntou.edu.tw

Follow this and additional works at: https://jmstt.ntou.edu.tw/journal

Part of the Electrical and Computer Engineering Commons

\section{Recommended Citation}

Chang, Koan-Yuh and Chang, Wen-Jer (2008) "MULTI-OBJECTIVE CONTROL DESIGN FOR STOCHASTIC LARGESCALE SYSTEMS BASED ON LMI APPROACH AND SLIDING MODE CONTROL CONCEPT," Journal of Marine Science and Technology. Vol. 16: Iss. 3, Article 5.

DOI: $10.51400 / 2709-6998.2006$

Available at: https://jmstt.ntou.edu.tw/journal/vol16/iss3/5

This Research Article is brought to you for free and open access by Journal of Marine Science and Technology. It has been accepted for inclusion in Journal of Marine Science and Technology by an authorized editor of Journal of Marine Science and Technology. 
MULTI-OBJECTIVE CONTROL DESIGN FOR STOCHASTIC LARGE-SCALE SYSTEMS BASED ON LMI APPROACH AND SLIDING MODE CONTROL CONCEPT

Acknowledgements

This research was supported in part by the National Science Council of Taiwan, ROC, under the Grant NSC 93-2218-E270-003.

This research article is available in Journal of Marine Science and Technology: https://jmstt.ntou.edu.tw/journal/ 


\title{
MULTI-OBJECTIVE CONTROL DESIGN FOR STOCHASTIC LARGE-SCALE SYSTEMS BASED ON LMI APPROACH AND SLIDING MODE CONTROL CONCEPT
}

\author{
Koan-Yuh Chang* and Wen-Jer Chang**
}

\begin{abstract}
Key words: stochastic large-scale systems, sliding mode control, upper bound covariance control, pole placement and linear matrix inequality approach.
\end{abstract}

\begin{abstract}
In this paper, a controller $u_{i}(t)$ is designed for stochastic large-scale systems to achieve the following three objectives simultaneously: the pole placement constraint, $H_{\infty}$ norm constraint and individual state variance constraint. In terms of the invariance property of sliding mode control, both the uncertain interconnection terms and an unknown nonlinear function will disappear on the sliding mode. Then, with the aid of upper bound covariance control theory, pole placement skill and $H_{\infty}$ norm control theory, a controller, in which the control feedback gain matrix $G_{i}$ is synthesized using linear matrix inequality approach, is derived to achieve the above multiple objectives. Finally, a simulation example is presented to illustrate the proposed method.
\end{abstract}

\section{INTRODUCTION}

It is known that some control objectives, such as the robust stability and noise attenuation, can be achieved if certain $H_{\infty}$ bounds are maintained [17]. Hence, there have been lots of papers studying the feedback controller design with $H_{\infty}$ norm constraints (see [1], [16] and [36]). In practice, we are always required to develop some ways for designing controllers to achieve multi-objective performance. [2] and [34] have discussed the $H_{\infty}$ norm and variance constrained problem simultaneously. However, a Riccati equation approach applied to minimize a scalar cost index does not ensure satisfaction of individual variance constraints. A more straightforward method for designing controllers to achieve variance constraints of

Paper submitted 05/16/07; accepted 09/03/07. Author for correspondence: Wen-Jer Chang (e-mail:wjchang@mail.ntou.edu.tw).

*Department of Electronic Engineering, Chienkuo Technology University, Changhua 500, Taiwan, R.O.C.

**Department of Marine Engineering, National Taiwan Ocean University, Keelung 202, Taiwan, R. O. C. individual states is developed in [10], [13], [14], [19] and [32]. However, the approach described in [14] and [19] does not consider the presence of system perturbations; the closed-loop system may be unstable when it suffers from perturbations. An improved control method, called upper bound covariance control (UBCC), which satisfies variance constraints with perturbations is proposed in [10], [13], and [32]. Nevertheless, the drawback of the direct UBCC approach is that the state feedback gain designed in [10], [13], and [32] will become very large when the systems suffer from large perturbations. If a system is large-scale and the interconnections of the systems are uncertain then it is hard to design the state feedback control by using UBCC method directly. Based on the concept of sliding mode control (SMC) and with the aid of UBCC, a new control method is developed for the problems of local state upper bound covariance control (LSUBCC) in stochastic uncertain large-scale systems [6]. In [6], the aim of the so-called LSUBCC is to achieve the upper bound covariance control for each subsystem in the large-scale systems.

Pole location is directly associated with performance specifications, such as the settling time and rise time of a control system. The system poles are, in fact, not necessarily specified at exact locations, but assigned to a region (see [18], [21], [23] and [33]). For the regional pole constraint, a typical rule for evaluating the relative stability of closed-loop systems is to judge whether all of the poles are located within a prescribed circular region (Fig. 1). This specified circular region with center at $-q_{i}+j 0\left(q_{i}>0\right)$ and radius $\rho_{i},\left(\rho_{i}<q_{i}\right)$ is denoted by $\mathscr{D}\left(-q_{i}, \rho_{i}\right)$. This constraint is one of the most frequently employed performance requirements in system control design problems.

Owing to the advantages of simple design, easy implementation and insensitivity to system perturbations, the technique of SMC has become a successful synthesis method for a system control design and has been applied to many complex systems such as [15], [20], [22], [24], [27], [28] and [31]. The main characteristic of a SMC system is that the system dynamics in the sliding mode is made to be invariant if parameter uncertainties and/or perturbations satisfy a certain matching condition. However, the SMC for stochastic systems has been receiving relatively little attention until recently [5-9, 30]. Based on the concept of SMC design, [7] and [30] addressed the co- 


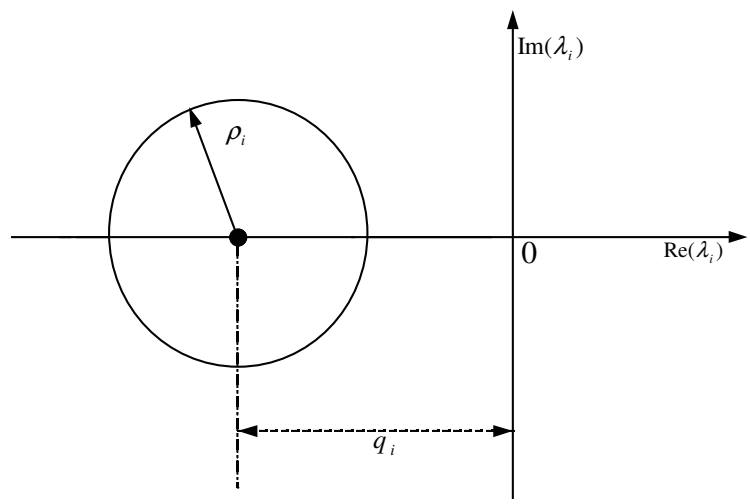

Fig. 1. Pole location region $\mathscr{D}\left(-q_{i}, \rho_{i}\right)$.

variance control problems in the case of stochastic model reference systems. In [8] and [9], the authors successfully extended the above approach to linear perturbed systems. Also, the authors applied this combined technique to deal with the covariance controller design problems for stochastic large-scale systems [5] and [6]. As an extension of the results in [5] and [6] and using the linear matrix inequality (LMI) method, this paper will deal with the same systems but involves a perturbations with nonlinear unknown function. Then, a useful controller is design which can force the systems to simultaneously achieve specified pole location constraints, $H_{\infty}$ norm constraints, and individual variance constraints. Therefore, this proposed controller design will enable a quick and accurate response, noise attenuation, and robust stability. Here, we would like to point out that, according to recent research, some authors [25] are interested to follow our approach [7] to deal with the problems of uncertain stochastic systems with time-varying delay. Because LMI's intrinsically reflect constraints rather than optimality, many papers tend to offer more flexibility by combining several constraints on the system [4], [11] and [12]. Moreover, software like MatLab LMI Control Toolbox is now available to solve such LMI's in a fast and user-friendly manner.

This paper is organized as follows. Section 2 describes the system structure, formulates the design problems and also discusses on the issues related to the sliding phase and hitting phase of the system. In Section 3, the control feedback gain matrix $G_{i}$ is constructed by using LMI method to satisfy multi-objective constraints. Also, a numerical example for the problem of stochastic large-scale systems is demonstrated in Section 4 to verify the proposed approach. Finally, a conclusion is made in Section 5. Here, we pre-define some notations which will be used in the consequent sections: $\|z(t)\|$ and $\|M\|$ are 2-norm and induced 2-norm of the vector $z(t)$ and the matrix $M$ respectively. $\|z(t)\|_{1}$ is 1 -norm of the vector $z(t),(\cdot)^{T}$ is the transposition; $(\cdot)^{*}$ is the conjugate transpose and $\lambda(\cdot)$ is the eigenvalues. Moreover, a sign function $S_{i q}(t)$ is defined as

$$
\operatorname{sgn}\left(S_{i q}(t)\right)=\left\{\begin{array}{ll}
1 & S_{i q}(t)>0 \\
0 & S_{i q}(t)=0 \\
-1 & S_{i q}(t)<0
\end{array}(\text { see }[35]) .\right.
$$

\section{SYSTEM DESCRIPTION AND PROBLEM FORMULATION}

\section{System Description}

Consider a linear time-invariant large-scale system consisting of $n$ uncertain interconnected stochastic subsystems established on a filtered probability space $\left(\Omega, \boldsymbol{F},\left(\boldsymbol{F}_{t}\right)_{t \in R^{+}}, \boldsymbol{P}\right)$ and each subsystem is described as

$$
\begin{gathered}
\dot{x}_{i}(t)=A_{i} x_{i}+B_{i}\left(u_{i}(t)+f_{i}\left(x_{i}(t)\right)\right)+\sum_{\substack{j=1 \\
j \neq i}}^{n} A_{i j} x_{j}(t)+D_{i} w_{i}(t), i=1,2, \cdots, n \\
y_{i}(t)=F_{i} x_{i}(t)
\end{gathered}
$$

where $x_{i}(t) \in R^{n_{i} \times 1}, u_{i}(t) \in R^{m_{i} \times 1}$, and $w_{i}(t) \in R^{m_{i} \times 1}$ are the state variable, control and white noise of the $i$ - th subsystem, respectively. $A_{i}$ and $A_{i j} \in R^{n_{i} \times n_{i}} ; B_{i}$ and $D_{i} \in R^{n_{i} \times m_{i}}$; $F_{i} \in R^{m_{i} \times n_{i}}$, where $A_{i j}$ is a bounded uncertainty satisfying $\left\|A_{i j}\right\| \leq \eta_{i j}$. Here, $f_{i}\left(x_{i}(t)\right) \in R^{m_{i} \times 1}$ is unknown nonlinear function satisfying

$$
\left\|f_{i}\left(x_{i}(t)\right)\right\| \leq \beta_{i}\left\|x_{i}(t)\right\|
$$

with $\beta_{i}>0$ a known constant. Moreover, we suppose that $n_{i}>m_{i}$ is satisfied and the white noise $w_{i}(t)$ of (1) satisfies (3) $E\left(w_{i}(t)\right)=0, E\left(x_{i}(0) w_{i}^{T}(t)\right)=0, E\left(w_{i}(t) w_{i}^{T}(t)\right) \triangleq W_{i}=I_{i}$, where $x_{i}(0)$ denotes the initial state and $I_{i}$ denotes the identity matrix. Assume that $\left(A_{i}, B_{i}\right)$ is a stabilizable pair and $A_{i j}$ satisfies the matching condition (4)

$$
\operatorname{rank}\left[B_{i}: A_{i j}\right]=\operatorname{rank}\left[B_{i}\right] .
$$

\section{Problem Formulation of the Controller Design}

Now, the goal of this paper is to design the control $u_{i}(t)$ for each subsystem to satisfy the following objectives.

\section{Objective (i): Constraints on pole placement region}

The issue of transient response of the designed closed-loop system is addressed by properly specifying the locations of its poles. In this paper, the pole placement region in the complex $z_{i}-$ plane is described by the LMI condition [12]

$$
\mathscr{D}=\left\{z_{i} \in \mathcal{C}: f_{\mathscr{D}}\left(z_{i}\right)=U_{i}+z_{i} N_{i}+\bar{z}_{i} N_{i}^{T}<0\right\}
$$

where $\mathcal{C}$ denotes the set of complex number; $U_{i}=U_{i}^{T}$ and $N_{i}$ are real matrix parameters for choosing a suitable convex region by defining the characteristic function $f_{\mathscr{D}}\left(z_{i}\right)$. Specifically, we 
consider the region of the disk $\mathscr{D}\left(-q_{i}, \rho_{i}\right)$ with center at $\left(-q_{i}, 0\right)$ and radius $0<\rho_{i}<q_{i}$ for the closed-loop pole of the system. The disk region $\mathscr{D}\left(-q_{i}, \rho_{i}\right)$ in the complex plane $z_{i}=\hat{x}_{i}+j \hat{y}_{i}$ can be described as

$$
\left(q_{i}+\hat{x}_{i}\right)^{2}+\hat{y}_{i}^{2}=\left(q_{i}+z_{i}\right)\left(q_{i}+\bar{z}_{i}\right)<\rho_{i}^{2} .
$$

By the property of Schur's complement [4], we have the characteristic function $f_{\mathscr{D}}\left(z_{i}\right)$ of (6) within the disk region $\mathscr{D}\left(-q_{i}, \rho_{i}\right)$ as follows:

$$
f_{\mathscr{D}}\left(z_{i}\right)=\left[\begin{array}{cc}
-\rho_{i} & q_{i}+z_{i} \\
q_{i}+\bar{z}_{i} & -\rho_{i}
\end{array}\right]<0 .
$$

In comparison with the definition of LMI condition in (5), the matrix parameters for the disk region $\mathscr{D}\left(-q_{i}, \rho_{i}\right)$ are

$$
U_{i}=\left[\begin{array}{cc}
-\rho_{i} & q_{i} \\
q_{i} & -\rho_{i}
\end{array}\right], \quad N_{i}=\left[\begin{array}{ll}
0 & 1 \\
0 & 0
\end{array}\right]
$$

The considered system (1) is called $\mathscr{D}$-stable if the eigenvalues of the system are located in the disk region as shown in Fig. 1, i.e.,

$$
\lambda\left(A_{i}+B_{i} G_{i}\right) \in \mathscr{D}\left(-q_{i}, \rho_{i}\right) .
$$

That is, the closed-loop poles of the system are specified in terms of the system matrix $A_{i}+B_{i} G_{i}$ and required to lie within the disk region $\mathscr{D}\left(-q_{i}, \rho_{i}\right)$ with suitable chosen parameters $q_{i}>\rho_{i}>0$.

\section{Objective (ii): Constraints on $H_{\infty}$ norm}

In the system (1), the effect of the noise input $w_{i}(t)$ on the output $y_{i}(t)$ should be kept small for the system. Under the assumption, the system (1) is controlled to be stable, let $H_{i}(s)$ denote the closed-loop transfer function from $w_{i}(t)$ to $y_{i}(t)$. The desired $H_{\infty}$ performance level is described as (10)

$$
\left\|H_{i}(s)\right\|_{\infty}=\sup \frac{\left(E \int_{0}^{\infty} y_{i}^{T}(t) y_{i}(t) d t\right)^{1 / 2}}{\left(E \int_{0}^{\infty} w_{i}^{T}(t) w_{i}(t) d t\right)^{1 / 2}}<\gamma_{i}
$$

where the performance level upper bound $\gamma_{i}$ can be implemented as a constraint to be met or a parameter to be minimized during the controller construction.

\section{Objective (iii): Constraints on upper bound of local state covariance}

Besides the signal amplitude considered in the output channel, we are also interested in the state covariance of the system (1) induced by the external disturbance input $w_{i}(t)$. The individual steady state variance of each subsystem satisfies the following constraint:

$$
\left[X_{k k}\right]_{i} \triangleq \operatorname{Var}\left(x_{i k}(t)\right) \leq\left[\tilde{X}_{k k}\right]_{i} \leq\left(\sigma_{k}^{2}\right)_{i} \quad k=1,2, \cdots, n_{i}
$$

where $\operatorname{Var}\left(x_{i k}(t)\right)$ and $\left(\sigma_{k}\right)_{i}$, respectively, denote the $k-$ th variance value and root mean square (RMS) constraints for variance of the $i$-th subsystem, $\left[\tilde{X}_{k k}\right]_{i}$ denotes the $k$-th diagonal element of local state upper bound covariance matrix $\tilde{X}_{i},\left[X_{k k}\right]_{i}$ denotes the $k$-th diagonal element of the matrix $X_{i}$. Here, $X_{i}$ denotes the local state covariance matrix of the $i$ - th subsystem within the definition of following

$$
X_{i}=\lim _{t \rightarrow \infty} E\left(x_{i}(t) x_{i}^{T}(t)\right)
$$

Remark 1: The objective (iii) is called the LSUBCC problem [6].

It is seen from (1a), the presence of the uncertain interconnected term $\sum_{\substack{j=1 \\ j \neq i}}^{n} A_{i j} x_{j}(t)$ and unknown nonlinear function $f_{i}\left(x_{i}(t)\right)$ not only will make the LSUBCC problem with state feedback control be much more difficult but also let the multiple objectives for system requirement design become harder. In order to overcome these difficulties, the invariance property of SMC may be a good way to handle the problems. From our previous work [6], the following subsections 2.3 and 2.4 are reviewed briefly. The details, contained lemmas and proofs of lemma, can be found in [6].

\section{Sliding Phase of the System}

First, we define the switching function $S_{i}(t)$ corresponding to the $i-$ th subsystem as follows

$$
S_{i}(t)=C_{i} x_{i}(t)-\int_{0}^{t}\left(C_{i} A_{i}+C_{i} B_{i} G_{i}\right) x_{i}(\tau) d \tau
$$

where $S_{i}(t)=\left[\begin{array}{lllll}S_{i 1}(t) & \cdots & S_{i q}(t) & \cdots & S_{i m_{i}}(t)\end{array}\right]^{T} \in R^{m_{i} \times 1} ; C_{i}$ and $G_{i} \in R^{m_{i} \times n_{i}}$ are constant matrices to be designed. $C_{i}$ is chosen such that $C_{i} B_{i} \neq 0$ and $C_{i} D_{i}=0$, and $G_{i}$ is the control feedback gain matrix to be determined so that the local state covariance can fit the requirement in the sliding mode. The switching function $S_{i}(t)$ in (13) is well defined for the solution $x_{i}(t)$ of the system (1).

Differentiating the equation (13) with respect to time, choosing $C_{i} D_{i}=0$ and using equation (1), we obtain $\dot{S}_{i}(t)=C_{i} \sum_{\substack{j=1 \\ j \neq i}}^{n} A_{i j} x_{j}(t)+C_{i} B_{i} u_{i}(t)+C_{i} B_{i} f_{i}\left(x_{i}(t)\right)-C_{i} B_{i} G_{i} x_{i}(t)$. In the sliding mode, $\dot{S}_{i}(t)=0$ holds, then we get the equivalent control as follows

$$
u_{i e q}(t)=G_{i} x_{i}(t)-\left(C_{i} B_{i}\right)^{-1} C_{i} \sum_{\substack{j=1 \\ j \neq i}}^{n} A_{i j} x_{j}(t)-f_{i}\left(x_{i}(t)\right) .
$$

Substituting $u_{i e q}(t)$ into (1), the sliding mode dynamic equation is 


$$
\begin{gathered}
\dot{x}_{i}(t)=\left(A_{i}+B_{i} G_{i}\right) x_{i}(t)+\left(I_{i}-B_{i}\left(C_{i} B_{i}\right)^{-1} C_{i}\right) \sum_{\substack{j=1 \\
j \neq i}}^{n} A_{i j} x_{j}(t)+D_{i} w_{i}(t) \\
y_{i}(t)=F_{i} x_{i}(t) .
\end{gathered}
$$

If $\sum_{\substack{j=1 \\ j \neq i}}^{n} A_{i j} x_{j}(t)$ is regarded as a disturbance and (4) holds, by the invariance property of SMC, the dynamics (15) is insensitive to the disturbance. Thus (15) is reduced to

$$
\begin{gathered}
\dot{x}_{i}(t)=\left(A_{i}+B_{i} G_{i}\right) x_{i}(t)+D_{i} w_{i}(t) \\
y_{i}(t)=F_{i} x_{i}(t) .
\end{gathered}
$$

\section{Hitting Phase of the System}

This subsection tries to find the controller $u_{i}(t)$ on the $i-$ th subsystem such that the states of the system (1) can be forced to the sliding surface. Let us define a Lyapunov function for each subsystem as

$$
V_{i}\left(S_{i}(t)\right)=S_{i}^{T}(t) S_{i}(t)=S_{i 1}^{2}(t)+\cdots+S_{i q}^{2}(t)+\cdots+S_{i m_{i}}^{2}(t) .
$$

From our previous work [6], one has the following results.

Lemma 2.1 [6]

Consider the system (1) with the solution $x_{i}(t)$. If a Lyapunov function $V_{i}\left(S_{i}(t)\right)$ is given as (17), (3) holds and $C_{i} D_{i}=0$ is chosen, then we have

$$
\frac{d}{d t} V_{i}\left(S_{i}(t)\right)=2 S_{i}^{T}(t) \dot{S}_{i}(t) .
$$

\section{Lemma 2.2 [6]}

Consider the system (1), if $C_{i} D_{i}=0$ and let the controller $u_{i}(t)$ be

$$
\begin{aligned}
& u_{i}(t)=G_{i} x_{i}(t)-\left(C_{i} B_{i}\right)^{-1}\left[k_{i}\left\|C_{i}\right\| \cdot \sum_{\substack{j=1 \\
j \neq i}}^{n}\left\|x_{j}(t)\right\|+\beta_{i}\left\|C_{i}\right\| \cdot\left\|B_{i}\right\| \cdot\left\|x_{i}(t)\right\|+\alpha_{i}\right] \operatorname{sgn}\left(S_{i}(t)\right), \\
& i=1,2, \cdots, n
\end{aligned}
$$

where $k_{i}>\max _{1 \leq j \leq n} \eta_{i j}, \alpha_{i}$ is an arbitrary positive number and $\operatorname{sgn}\left(S_{i}(t)\right)=\left[\begin{array}{lllll}\operatorname{sgn}\left(S_{i 1}(t)\right) & \cdots & \operatorname{sgn}\left(S_{i q}(t)\right) & \cdots & \operatorname{sgn}\left(S_{i m_{i}}(t)\right)\end{array}\right]^{T}$. Then the state $x_{i}(t)$ will be forced to the sliding surface.

\section{Proof:}

Differentiating (13) and choosing $C_{i} D_{i}=0$ and multiplying it by $S_{i}(t)$, we get

$$
\begin{aligned}
& S_{i}^{T}(t) \dot{S}_{i}(t)= \\
& S_{i}^{T}(t)\left[C_{i} B_{i} u_{i}(t)+C_{i} \sum_{\substack{j=1 \\
j \neq i}}^{n} A_{i j} x_{j}(t)+C_{i} B_{i} f_{i}\left(x_{i}(t)\right)-C_{i} B_{i} G_{i} x_{i}(t)\right] .
\end{aligned}
$$

$$
\begin{aligned}
& S_{i}^{T}(t) \dot{S}_{i}(t)=S_{i}^{T}(t)\left[C_{i} \sum_{\substack{j=1 \\
j \neq i}}^{n} A_{i j} x_{j}(t)-\right. \\
& \left.\left(k_{i}\left\|C_{i}\right\| \cdot \sum_{\substack{j=1 \\
j \neq i}}^{n}\left\|x_{j}(t)\right\|+\beta_{i}\left\|C_{i}\right\| \cdot\left\|B_{i}\right\| \cdot\left\|x_{i}(t)\right\|+\alpha_{i}\right) \cdot \operatorname{sgn}\left(S_{i}(t)\right)+C_{i} B_{i} f_{i}\left(x_{i}(t)\right)\right] .
\end{aligned}
$$

Therefore, (18) becomes

$\frac{d}{d t} V_{i}\left(S_{i}(t)\right)=2 S_{i}^{T}(t) C_{i} \sum_{\substack{j=1 \\ j \neq i}}^{n} A_{i j} x_{j}(t)-2 k_{i}\left\|C_{i}\right\| \cdot \sum_{\substack{j=1 \\ j \neq i}}^{n}\left\|x_{j}(t)\right\| \cdot\left\|S_{i}(t)\right\|_{1}-2 \beta_{i}\left\|C_{i}\right\| \cdot\left\|B_{i}\right\| \cdot\left\|x_{i}(t)\right\| \cdot\left\|S_{i}(t)\right\|_{1}$

$-2 \alpha_{i}\left\|S_{i}(t)\right\|_{1}+2 S_{i}^{T}(t) C_{i} B_{i} f_{i}\left(x_{i}(t)\right)$

$\leq 2\left|S_{i}^{T}(t) C_{i} \sum_{\substack{j=1 \\ j \neq i}}^{n} A_{i j} x_{j}(t)\right|-2 k_{i}\left\|C_{i}\right\| \cdot \sum_{\substack{j=1 \\ j \neq i}}^{n}\left\|x_{j}(t)\right\| \cdot\left\|S_{i}(t)\right\|_{1}-2 \beta_{i}\left\|C_{i}\right\|\left\|B_{i}\right\| \cdot\left\|x_{i}(t)\right\| \cdot\left\|S_{i}(t)\right\|_{1}$ $+2\left|S_{i}^{T}(t) C_{i} B_{i} f_{i}\left(x_{i}(t)\right)\right|-2 \alpha_{i}\left\|S_{i}(t)\right\|_{1}$

$\leq 2\left\|C_{i}\right\| \sum_{\substack{j=1 \\ j \neq i}}^{n}\left\|A_{i j}\right\|\left\|x_{j}(t)\right\|\left\|S_{i}(t)\right\|-2 k_{i}\left\|C_{i}\right\| \cdot \sum_{\substack{j=1 \\ j \neq i}}^{n}\left\|x_{j}(t)\right\| \cdot\left\|S_{i}(t)\right\|_{1}-2 \beta_{i}\left\|C_{i}\right\| \cdot\left\|B_{i}\right\| \cdot\left\|x_{i}(t)\right\| \cdot\left\|S_{i}(t)\right\| \|_{1}$ $+2\left\|C_{i}\right\| \cdot\left\|B_{i}\right\| \cdot\left\|f_{i}\left(x_{i}(t)\right)\right\| \cdot\left\|S_{i}(t)\right\|-2 \alpha_{i}\left\|S_{i}(t)\right\|_{1}$

$\leq 2\left\|C_{i}\right\|\left(\max _{1 \leq j \leq n} \eta_{i j}\right) \sum_{\substack{j=1 \\ j \neq i}}^{n}\left\|x_{j}(t)\right\| \cdot\left\|S_{i}(t)\right\|-2 k_{i}\left\|C_{i}\right\| \cdot \sum_{\substack{j=1 \\ j \neq i}}^{n}\left\|x_{j}(t)\right\| \cdot\left\|S_{i}(t)\right\|\left\|_{1}-2 \beta_{i}\right\| C_{i}\|\| B_{i}\|\cdot\| x_{i}(t)\|\cdot\| S_{i}(t) \|_{1}$ $+2\left\|C_{i}\right\| \cdot\left\|B_{i}\right\| \cdot\left\|f_{i}\left(x_{i}(t)\right)\right\| \cdot\left\|S_{i}(t)\right\|-2 \alpha_{i}\left\|S_{i}(t)\right\|_{1}$

$\leq-2 \alpha_{i}\left\|S_{i}(t)\right\|<0$

where $\left\|S_{i}(t)\right\| \leq\left\|S_{i}(t)\right\|_{1}, k_{i}>\max _{1 \leq j \leq n}\left\|\eta_{i j}\right\|$ and equation (2) are used. That means the state $x_{i}(t)$ will be forced to reach the sliding surface. The proof is completed.

Remark 2: Lemma 2.2 can be derived from the Theorem 4.1 of [6] with suitable modification.

\section{DESIGN OF CONTROL FEEDBACK GAIN MATRIX $G_{i}$ TO SATISFY THE MULTIPLE OBJECTIVES}

In this section, the design of control feedback gain matrix $G_{i}$ is constructed for the system (16) to achieve the multi-objective performance constraints in terms of suitable LMI conditions. It was known that local state covariance $X_{i}$ defined in (12) satisfies the following Lyapunov equation

$$
\left(A_{i}+B_{i} G_{i}\right) X_{i}+X_{i}\left(A_{i}+B_{i} G_{i}\right)^{T}+D_{i} D_{i}^{T}=0 .
$$

Equation (24) was proposed for a system's stability design [1] and served as the starting point of the derivation in this paper.

\section{Constraints on Pole Placement Region}

This subsection will derive a constraint, which can be found in Lemma 3.2, for pole placement on system (16). To attain this goal, the following Lemma 3.1 is helpful. 


\section{Lemma 3.1:}

Consider the system (16). Let $G_{i}$ be given and $\gamma_{i}>0$ be a fixed scalar. If there exists a positive definite matrix $\tilde{X}_{i}$ satisfying

$$
\begin{aligned}
& \left(A_{i}+B_{i} G_{i}\right) \tilde{X}_{i}+\tilde{X}_{i}\left(A_{i}+B_{i} G_{i}\right)^{T}+\gamma_{i}^{-2} \tilde{X}_{i} \tilde{R}_{i} \tilde{X}_{i}+D_{i} D_{i}^{T}+ \\
& q_{i}^{-1}\left(A_{i}+B_{i} G_{i}\right) \tilde{X}_{i}\left(A_{i}+B_{i} G_{i}\right)^{T}+q_{i}^{-1}\left(q_{i}^{2}-\rho_{i}^{2}\right) \tilde{X}_{i}=0
\end{aligned}
$$

where $\tilde{R}_{i}=F_{i}^{T} F_{i}$. Then all the closed-loop poles of $\left(A_{i}+B_{i} G_{i}\right)$ are located within $\mathscr{D}\left(-q_{i}, \rho_{i}\right)$ and $\left\|H_{i}(s)\right\|_{\infty} \leq \gamma_{i}$. Furthermore, in this case, we have $X_{i} \leq \tilde{X}_{i}$.

\section{Proof:}

Let $\lambda_{i}$ and $v_{i} \in \mathcal{C}$ (complex), respectively, be the eigenvalue and the right eigenvector of $\left(A_{i}+B_{i} G_{i}\right)$, then $\left(A_{i}+B_{i} G_{i}\right) v_{i}=\lambda_{i} v_{i}$ and $\left(A_{i}+B_{i} G_{i}\right)^{T} v_{i}=\bar{\lambda}_{i} v_{i} \quad$ in which $\lambda_{i}=\hat{x}_{i}+j \hat{y}_{i}$ and $\bar{\lambda}_{i}=\hat{x}_{i}-j \hat{y}_{i}$. Substituting this expression into (25), we have

$v_{i}^{*}\left[\lambda_{i} \tilde{X}_{i}+\bar{\lambda}_{i} \tilde{X}_{i}+q_{i}^{-1} \lambda_{i} \bar{\lambda}_{i} \tilde{X}_{i}+q_{i}^{-1}\left(q_{i}^{2}-\rho_{i}^{2}\right) \tilde{X}_{i}\right] v_{i}=-v_{i}^{*}\left(\gamma_{i}^{-2} \tilde{X}_{i} \tilde{R}_{i} \tilde{X}_{i}+D_{i} D_{i}^{T}\right) v_{i}$

$\Rightarrow\left[2 \hat{x}_{i}+q_{i}^{-1}\left(\hat{x}_{i}^{2}+\hat{y}_{i}^{2}\right)+q_{i}^{-1}\left(q_{i}^{2}-\rho_{i}^{2}\right)\right] v_{i}^{*} \tilde{X}_{i} v_{i}=-v_{i}^{*}\left(\gamma_{i}^{-2} \widetilde{X}_{i} \widetilde{R}_{i} \widetilde{X}_{i}+D_{i} D_{i}^{T}\right) v_{i}$

$\Rightarrow\left[q_{i}^{-1}\left(\hat{x}_{i}^{2}+2 \hat{x}_{i} q_{i}+q_{i}^{2}+\hat{y}_{i}^{2}-\rho_{i}^{2}\right)\right] v_{i}^{*} \tilde{X}_{i} v_{i}=-v_{i}^{*}\left(\gamma_{i}^{-2} \tilde{X}_{i} \widetilde{R}_{i} \tilde{X}_{i}+D_{i} D_{i}^{T}\right) v_{i}$.

Since $q_{i}>0, \tilde{X}_{i}>0$ and $\gamma_{i}^{-2} \tilde{X}_{i} \widetilde{R}_{i} \tilde{X}_{i}+D_{i} D_{i}^{T} \geq 0$, from (26) we obtain

$$
\begin{gathered}
{\left[q_{i}^{-1}\left(\hat{x}_{i}^{2}+2 \hat{x}_{i} q_{i}+q_{i}^{2}+\hat{y}_{i}^{2}-\rho_{i}^{2}\right)\right] v_{i}^{*} \tilde{X}_{i} v_{i}<0} \\
\Rightarrow\left(\hat{x}_{i}+q_{i}\right)^{2}+\hat{y}_{i}^{2}-\rho_{i}^{2}<0
\end{gathered}
$$

which means that all eigenvalues of $\left(A_{i}+B_{i} G_{i}\right)$ should locate in a specified disk $\mathscr{D}\left(-q_{i}, \rho_{i}\right)$. Consider (25) and by the inducement of the Fact 1.2 of [29] we obtain $\left\|H_{i}(s)\right\|_{\infty} \leq \gamma_{i}$, since $q_{i}^{-1}\left(A_{i}+B_{i} G_{i}\right) \tilde{X}_{i}\left(A_{i}+B_{i} G_{i}\right)^{T}+q_{i}^{-1}\left(q_{i}^{2}-\rho_{i}^{2}\right) \tilde{X}_{i} \geq 0$. Subtracting (24) from (25) and using $\gamma_{i}^{-2} \tilde{X}_{i} \widetilde{R}_{i} \tilde{X}_{i}+q_{i}^{-1}\left(A_{i}+B_{i} G_{i}\right) \tilde{X}_{i}\left(A_{i}+B_{i} G_{i}\right)^{T}+q_{i}^{-1}\left(q_{i}^{2}-\rho_{i}^{2}\right) \tilde{X}_{i} \geq 0$, the inequality $X_{i} \leq \tilde{X}_{i}$ will be gotten from Theorem 4.2 of [21] due to the fact that $\left(A_{i}+B_{i} G_{i}\right)$ is stable.

The proof is completed.

\section{Lemma 3.2}

Consider the system (16). If there exist positive definite matrix $\tilde{X}_{i}$ and matrix $L_{i}$ satisfying

$$
\left[\begin{array}{cc}
-\rho_{i} \tilde{X}_{i} & A_{i} \tilde{X}_{i}+B_{i} L_{i}+q_{i} \tilde{X}_{i} \\
q_{i} \tilde{X}_{i}+\tilde{X}_{i} A_{i}^{T}+L_{i}^{T} B_{i}^{T} & -\rho_{i} \tilde{X}_{i}
\end{array}\right]<0
$$

where $L_{i}=G_{i} \tilde{X}_{i}$. Then the closed-loop poles of $A_{i}+B_{i} G_{i}$ are located within disk LMI region $\mathscr{D}\left(-q_{i}, \rho_{i}\right)$.

\section{Proof:}

Given a prescribed disk LMI region $\mathscr{D}\left(-q_{i}, \rho_{i}\right)$ in the left-hand side of complex $z_{i}$-plane, and the matrix $\left(A_{i}+B_{i} G_{i}\right)$ of the system (16) is $\mathscr{D}$-stable (i.e., $\left.\lambda_{i}\left(A_{i}+B_{i} G_{i}\right) \in \mathscr{D}\left(-q_{i}, \rho_{i}\right)\right)$. Then, from Lemma 3.1, there exists a positive definite matrix $\tilde{X}_{i}$ satisfying

$\left(A_{i}+B_{i} G_{i}\right) \tilde{X}_{i}+\tilde{X}_{i}\left(A_{i}+B_{i} G_{i}\right)^{T}+q_{i}^{-1}\left(\left(A_{i}+B_{i} G_{i}\right) \tilde{X}_{i}\left(A_{i}+B_{i} G_{i}\right)^{T}+\left(q_{i}^{2}-\rho_{i}^{2}\right) \tilde{X}_{i}\right)<0 . \quad$ (30) Equation (30) has the form of (27) with $\lambda_{i}\left(A_{i}+B_{i} G_{i}\right) \in \mathscr{D}\left(-q_{i}, \rho_{i}\right)$ and can deduce to (28) which is in fact the same as (6). Therefore, the matrix inequality for $\mathscr{D}$-stability (30) is equivalent to the pole placement condition (7).

The feasibility of pole region (7) is equal to the matrix inequality condition

$$
M_{D}\left(\hat{A}_{i}, \tilde{X}_{i}\right)=U \otimes \tilde{X}_{i}+N \otimes\left(\hat{A}_{i} \tilde{X}_{i}\right)+N^{T} \otimes\left(\hat{A}_{i} \tilde{X}_{i}\right)^{T}<0
$$

where $\otimes$ denotes the Kronecker product of matrices. Equation (31) was proven in [11] and as a counterpart of Gutman's theorem for LMI regions. Since the expressions of $M_{D}\left(\hat{A}_{i}, \tilde{X}_{i}\right)$ in (31) and $f_{\mathscr{D}}\left(z_{i}\right)$ in (7) are related by the substitution $\left(\tilde{X}_{i}, \quad \hat{A}_{i} \tilde{X}_{i}, \quad \tilde{X}_{i} \hat{A}_{i}^{T}\right) \leftrightarrow\left(1, \quad z_{i}, \quad \bar{z}_{i}\right)$, the matrix inequality condition for the disk region $\mathscr{D}\left(-q_{i}, \rho_{i}\right)$ as shown in (7) can be written as

$$
\left[\begin{array}{cc}
-\rho_{i} \tilde{X}_{i} & q_{i} \tilde{X}_{i}+\hat{A}_{i} \tilde{X}_{i} \\
q_{i} \tilde{X}_{i}+\tilde{X}_{i} \hat{A}_{i}^{T} & -\rho_{i} \tilde{X}_{i}
\end{array}\right]<0 .
$$

By the substitution of $\hat{A}_{i}=A_{i}+B_{i} G_{i}$ and $L_{i}=G_{i} \tilde{X}_{i}$, we have the following LMI condition in terms of the matrix variables $\tilde{X}_{i}$ and $L_{i}$ for addressing the disk LMI region $\mathscr{D}\left(-q_{i}, \rho_{i}\right)$ constraints of the closed-loop poles:

$$
\left[\begin{array}{cc}
-\rho_{i} \tilde{X}_{i} & A_{i} \tilde{X}_{i}+B_{i} L_{i}+q_{i} \tilde{X}_{i} \\
q_{i} \tilde{X}_{i}+\tilde{X}_{i} A_{i}^{T}+L_{i}^{T} B_{i}^{T} & -\rho_{i} \tilde{X}_{i}
\end{array}\right]<0 .
$$

The proof is completed.

\section{Constraints on $H_{\infty}$ Norm}

In considering the performance related to both the amplitude attenuation level in the output channel and the presence of stochastic external input are based on the result of the Lyapunov equation in (24).

\section{Lemma 3.3}

In the system (16), let $\gamma_{i}>0$ be a fixed scalar. If there exist positive definite matrix $\tilde{X}_{i}$ and matrix $L_{i}$ such that the following LMI condition holds 


$$
\left[\begin{array}{cc}
A_{i} \tilde{X}_{i}+B_{i} L_{i}+\tilde{X}_{i} A_{i}^{T}+L_{i}^{T} B_{i}^{T}+D_{i} D_{i}^{T} & \tilde{X}_{i} F_{i}^{T} \\
F_{i} \tilde{X}_{i} & -\gamma_{i}^{-2} I_{i}
\end{array}\right]<0
$$

where $L_{i}=G_{i} \tilde{X}_{i}$. Then, the $H_{\infty}$ norm constraint (10) is satisfied. Furthermore, in this case, we have

$$
X_{i} \leq \tilde{X}_{i}
$$

\section{Proof:}

First, we define the Lyapunov function for the system dynamics (16) as following:

$$
V\left(x_{i}(t)\right)=x_{i}^{T}(t) \tilde{X}_{i}^{-1} x_{i}(t)
$$

where $\tilde{X}_{i}=\tilde{X}_{i}^{T}>0$ is the upper bound of $X_{i}$. According to Itô's differential rule [26], the time derivative of the quadratic Lyapunov function is

$$
\begin{aligned}
& \frac{d}{d t} V\left(x_{i}(t)\right)=x_{i}^{T}(t) \tilde{X}_{i}^{-1}\left(A_{i}+B_{i} G_{i}\right) x_{i}(t) \\
& +x_{i}^{T}(t)\left(A_{i}+B_{i} G_{i}\right)^{T} \tilde{X}_{i}^{-1} x_{i}(t)+\operatorname{trace}\left(D_{i}^{T} \tilde{X}_{i}^{-1} D_{i}\right) .
\end{aligned}
$$

The asymptotic stability of system (16) can be established if $\frac{d}{d t} V\left(x_{i}(t)\right)<0$ can be satisfied. Now, we can rewrite (10) to obtain

$$
\lim _{t \rightarrow \infty} \gamma_{i}^{-2} E\left[\int_{0}^{t} y_{i}^{T}(\tau) y_{i}(\tau) d \tau\right]-\lim _{t \rightarrow \infty} E\left[\int_{0}^{t} w_{i}^{T}(\tau) w_{i}(\tau) d \tau\right]<0 .
$$

Then, we define

$$
\begin{aligned}
J_{i}(t) & =E\left(\int_{0}^{1}\left[\gamma_{i}^{-2} y_{i}^{T}(\tau) y_{i}(\tau)-w_{i}^{T}(\tau) w_{i}(\tau)\right] d \tau\right) \\
& =E\left\{\int_{0}^{t}\left[\left[\gamma_{i}^{-2} y_{i}^{T}(\tau) y_{i}(\tau)-w_{i}^{T}(\tau) w_{i}(\tau)\right]+\frac{d V\left(x_{i}(\tau)\right)}{d \tau}\right) d \tau\right\}-E\left[V\left(x_{i}(\tau)\right)\right]+E\left[V\left(x_{i}(0)\right)\right] .
\end{aligned}
$$

Also we have

$$
\begin{aligned}
J_{i}(t) & \leq E\left\{\int_{0}^{t}\left(\left[\gamma_{i}^{-2} y_{i}^{T}(\tau) y_{i}(\tau)-w_{i}^{T}(\tau) w_{i}(\tau)\right]+\frac{d V\left(x_{i}(\tau)\right)}{d \tau}\right) d \tau\right\} \\
& =E\left\{\int_{0}^{t}\left(\left[\gamma_{i}^{-2}\left(x_{i}^{T}(\tau) F_{i}^{T} F_{i} x_{i}(\tau)\right)-w_{i}^{T}(\tau) w_{i}(\tau)\right]+\frac{d V\left(x_{i}(\tau)\right)}{d \tau}\right) d \tau\right\} .
\end{aligned}
$$

Substituting (37) into (39), then we can obtain

$$
\begin{aligned}
& J_{i}(t) \leq \\
& E\left(\int_{0}^{t}\left[\begin{array}{c}
x_{i}(\tau) \\
w_{i}(\tau)
\end{array}\right]^{T}\left[\begin{array}{cc}
\left(A_{i}+B_{i} G_{i}\right)^{T} \tilde{X}_{i}^{-1}+\tilde{X}_{i}^{-1}\left(A_{i}+B_{i} G_{i}\right)+\gamma_{i}^{-2} F_{i}^{T} F_{i} & \tilde{X}_{i}^{-1} D_{i} \\
D_{i}^{T} \tilde{X}_{i}^{-1} & -I_{i}
\end{array}\right]\left[\begin{array}{c}
x_{i}(\tau) \\
w_{i}(\tau)
\end{array}\right] d \tau\right) \cdot(40)
\end{aligned}
$$

By letting $t \rightarrow \infty$ and combining the condition in (38), the following inequality can be derived.

$$
\begin{aligned}
& E\left(\int_{0}^{\infty}\left[\begin{array}{c}
x_{i}(\tau) \\
w_{i}(\tau)
\end{array}\right]^{T}\left[\begin{array}{cc}
\left(A_{i}+B_{i} G_{i}\right)^{T} \tilde{X}_{i}^{-1}+\tilde{X}_{i}^{-1}\left(A_{i}+B_{i} G_{i}\right)+\gamma_{i}^{-2} F_{i}^{T} F_{i} & \tilde{X}_{i}^{-1} D_{i} \\
D_{i}^{T} \tilde{X}_{i}^{-1} & -I_{i}
\end{array}\right]\left[\begin{array}{l}
x_{i}(\tau) \\
w_{i}(\tau)
\end{array}\right] d \tau\right)(41) \\
& <0
\end{aligned}
$$

By Schur's complement, the inequality condition (41) is equivalent to

$$
\left(A_{i}+B_{i} G_{i}\right)^{T} \tilde{X}_{i}^{-1}+\tilde{X}_{i}^{-1}\left(A_{i}+B_{i} G_{i}\right)+\gamma_{i}^{-2} F_{i}^{T} F_{i}+\tilde{X}_{i}^{-1} D_{i} D_{i}^{T} \tilde{X}_{i}^{-1}<0 .
$$

Pre- and post-multiplying both sides of (42) by $\tilde{X}_{i}$, we then have

$$
\left(A_{i}+B_{i} G_{i}\right) \tilde{X}_{i}+\tilde{X}_{i}\left(A_{i}+B_{i} G_{i}\right)^{T}+\gamma_{i}^{-2} \tilde{X}_{i} F_{i}^{T} F_{i} \tilde{X}_{i}+D_{i} D_{i}^{T}<0 .
$$

Substituting $L_{i}=G_{i} \tilde{X}_{i}$ into (43) and using Schur's complement again, the inequality of (34) can be achieved. Moreover, subtracting (24) from (43), the inequality $X_{i} \leq \tilde{X}_{i}$ can also be obtained due to the positive item $\gamma_{i}^{-2} \tilde{X}_{i} F_{i}^{T} F_{i} \tilde{X}_{i}>0$. The proof is completed.

Remark 3: The equation (43) also can be derived from (25).

\section{Constraints on Upper Bound of Local State Covariance}

In this subsection, the upper bound of local state covariance constraint is deduced to the following Lemma 3.4.

\section{Lemma 3.4}

Consider the desired upper bound of local state covariance constraint on the system as described in (11). Let $\left(\sigma_{k}\right)_{i}>0$ is given. If there exists positive definite matrix $\tilde{X}_{i}$ such that the following LMI condition holds

$$
\left[\begin{array}{cc}
\left(\sigma_{k}^{2}\right)_{i} & I_{k i} \tilde{X}_{i} \\
\tilde{X}_{i} I_{k i}^{T} & \tilde{X}_{i}
\end{array}\right] \geq 0, k=1,2, \cdots, n_{i}
$$

where $I_{k i}=\left[\begin{array}{lllll}0 & \cdots & 1 & \cdots & 0\end{array}\right] \in R^{1 \times n_{i}}$ denotes a row vector with the $k$-th element is 1 and others are 0 . Then, the upper bound of local state covariance constraint can be achieved.

\section{Proof:}

Rewriting (11), one has

$$
I_{k i} \tilde{X}_{i} I_{k i}^{T} \leq\left(\sigma_{k}^{2}\right)_{i}, \quad k=1,2, \cdots, n_{i}
$$

or equivalently,

$$
\left(\sigma_{k}^{2}\right)_{i}-I_{k i} \tilde{X}_{i} \tilde{X}_{i}^{-1} \tilde{X}_{i} I_{k i}^{T} \geq 0, \quad k=1,2, \cdots, n_{i} .
$$

Using the property of Schur's complement [4], (45) can be reformulated as following inequality

$$
\left[\begin{array}{cc}
\left(\sigma_{k}^{2}\right)_{i} & I_{k i} \tilde{X}_{i} \\
\tilde{X}_{i} I_{k i}^{T} & \tilde{X}_{i}
\end{array}\right] \geq 0, k=1,2, \cdots, n_{i},
$$

which is the same as (46). Therefore the proof is completed.

Now, the individual LMI conditions as described in Lemma 3.2 3.4 for addressing various interesting performance constraints are summarized in the following main theorem.

\section{Main theorem}

In the system (16), given $\gamma_{i}>0,\left(\sigma_{k}\right)_{i}>0, \rho_{i}$ and $q_{i}>0$. The multi-objective performance constraints (i) (iii) as described in (5), (10) and (11) are satisfied if there exist positive 
definite matrix $\tilde{X}_{i}$ and matrix $L_{i}$ such that the following LMIs holds,

$$
\begin{gathered}
{\left[\begin{array}{cc}
A_{i} \tilde{X}_{i}+B_{i} L_{i}+\tilde{X}_{i} A_{i}^{T}+L_{i}^{T} B_{i}^{T}+D_{i} D_{i}^{T} & \tilde{X}_{i} F_{i}^{T} \\
F_{i} \tilde{X}_{i} & -\gamma_{i}^{-2} I_{i}
\end{array}\right]<0} \\
{\left[\begin{array}{cc}
-\rho_{i} \tilde{X}_{i} & A_{i} \tilde{X}_{i}+B_{i} L_{i}+q_{i} \tilde{X}_{i} \\
q_{i} \tilde{X}_{i}+\tilde{X}_{i} A_{i}^{T}+L_{i}^{T} B_{i}^{T} & -\rho_{i} \tilde{X}_{i}
\end{array}\right]<0} \\
{\left[\begin{array}{cc}
\left(\sigma_{k}^{2}\right)_{i} & I_{k i} \tilde{X}_{i} \\
\tilde{X}_{i} I_{k i}^{T} & \tilde{X}_{i}
\end{array}\right] \geq 0, k=1,2, \cdots, n_{i} .}
\end{gathered}
$$

Proof:

Following the proofs of Lemma 3.2 3.4, one knows that the multi-objective performance (i) (iii) can be achieved by the suitable convex optimization problem as shown in LMIs (48), (49) and (50). In other word, if matrices $\tilde{X}_{i}$ and $L_{i}$ exist and satisfy these LMIs, then the control feedback gain $G_{i}$ achieving the multi-objective performance constraints (i) (iii) can be synthesized by

$$
G_{i}=L_{i} \tilde{X}_{i}^{-1}
$$

The proof is completed.

Remark 4: By using the main theorem, one can minimize the $H_{\infty}$ performance level $\gamma_{i}$ for noise attenuation. Then, the resulting solution of the control feedback gain $G_{i}$ can also achieve the pole placement constraint as well as upper bound on local state covariance constraint.

Main theorem shows that the multi-objective (i) (iii) can be achieved by a convex optimization problem with LMI constraints. If the above LMIs are feasible, then we can obtain the control feedback gain $G_{i}$. In next section, a numerical example is provided to verify the proposed method. Now, one should check whether $\left\|H_{i}(s)\right\|_{\infty} \leq \gamma_{i}$ holds or not, the following lemma will be helpful.

\section{Lemma 3.5 [3]}

Consider the system (16). There exists a positive scalar $\gamma_{i}$ to satisfy $\left\|H_{i}(s)\right\|_{\infty} \leq \gamma_{i}$ if and only if $M_{\gamma_{i}}$ has no eigenvalues on the imaginary axis,

where $M_{\gamma_{i}} \triangleq\left[\begin{array}{cc}A_{i}+B_{i} G_{i} & \gamma_{i}^{-1} D_{i} D_{i}^{T} \\ -\gamma_{i}^{-1} F_{i}^{T} F_{i} & -\left(A_{i}+B_{i} G_{i}\right)^{T}\end{array}\right]$.

The design procedures presented in this paper is outlined as following

Initial status: The system (1) is given with certain assumptions in section 2 .

Objective: Find the controller $u_{i}(t)$ such that the goals (i), (ii) and (iii) are achieved.
Step 1: Choose $C_{i}$ to satisfy $C_{i} D_{i}=0$ and $C_{i} B_{i} \neq 0$.

Step 2: From the main theorem, get the feasible solution of control feedback gain $G_{i}$ as (51).

Step 3: Set the switching function $S_{i}(t)$ as (13).

Step 4: The controller $u_{i}(t)$ is obtained from (19).

\section{A NUMERICAL EXAMPLE}

A linear time-invariant stochastic large-scale system is written in the form of two subsystems

$$
\begin{aligned}
& \dot{x}_{1}(t)=A_{1} x_{1}(t)+B_{1}\left(u_{1}(t)+f_{1}\left(x_{1}(t)\right)\right)+A_{12} x_{2}(t)+D_{1} w_{1}(t) \\
& y_{1}(t)=F_{1} x_{1}(t) \\
& \dot{x}_{2}(t)=A_{2} x_{2}(t)+B_{2}\left(u_{2}(t)+f_{2}\left(x_{2}(t)\right)\right)+A_{21} x_{1}(t)+D_{2} w_{2}(t) \\
& y_{2}(t)=F_{2} x_{2}(t)
\end{aligned}
$$

where $\quad x_{1}(t)=\left[\begin{array}{ll}x_{11}(t) & x_{12}(t)\end{array}\right]^{T}, \quad A_{1}=\left[\begin{array}{cc}0 & 1 \\ -2 & 3\end{array}\right], \quad B_{1}=\left[\begin{array}{l}0 \\ 1\end{array}\right]$, $A_{12}=\delta\left[\begin{array}{ll}0 & 0 \\ 1 & 1\end{array}\right], D_{1}=\left[\begin{array}{l}1 \\ 0\end{array}\right], f_{1}\left(x_{1}(t)\right) \leq 0.6\left\|x_{1}(t)\right\|, F_{1}=\left[\begin{array}{ll}1 & 1\end{array}\right]$; $x_{2}(t)=\left[\begin{array}{ll}x_{21}(t) & x_{22}(t)\end{array}\right]^{T}, \quad A_{2}=\left[\begin{array}{cc}0 & 1 \\ -4 & 5\end{array}\right], \quad B_{2}=\left[\begin{array}{l}0 \\ 1\end{array}\right]$, $A_{21}=\delta\left[\begin{array}{ll}0 & 0 \\ 3 & 3\end{array}\right] \quad, \quad D_{2}=\left[\begin{array}{l}1 \\ 2\end{array}\right] \quad, \quad f_{2}\left(x_{2}(t)\right) \leq 0.4\left\|x_{2}(t)\right\| \quad$ and $F_{2}=\left[\begin{array}{ll}1 & 1\end{array}\right]$, in which $\delta \in[-1,1]$ is an uncertainty. The goal is to seek the control such that the steady state of the system satisfies the following requirements.

$$
\begin{aligned}
& q_{1}=16, \quad \rho_{1}=15 \\
& q_{2}=18, \quad \rho_{2}=17 \\
& \left\|H_{1}(s)\right\|_{\infty} \leq 1 \\
& \left\|H_{2}(s)\right\|_{\infty} \leq 0.8
\end{aligned}
$$

$$
\operatorname{Var}\left(x_{11}(t)\right)<2.5, \operatorname{Var}\left(x_{12}(t)\right)<3
$$

$$
\operatorname{Var}\left(x_{21}(t)\right)<1, \quad \operatorname{Var}\left(x_{22}(t)\right)<2 .
$$

Suppose $x_{1}(0)=\left[\begin{array}{ll}x_{11}(0) & x_{12}(0)\end{array}\right]^{T}=\left[\begin{array}{ll}4 & 7\end{array}\right]^{T}, x_{2}(0)=\left[\begin{array}{ll}x_{21}(0) & x_{22}(0)\end{array}\right]^{T}$ $=\left[\begin{array}{ll}5 & 8\end{array}\right]^{T}$ and the white noises $w_{1}(t)$ and $w_{2}(t)$ satisfy (3). Then, the proposed design procedure can be carried out as follows.

Step 1: Choosing $C_{1}=\left[\begin{array}{ll}0 & 1\end{array}\right]$ and $C_{2}=\left[\begin{array}{ll}-2 & 1\end{array}\right]$ such that $C_{1} D_{1}=0, C_{2} D_{2}=0$, and $C_{1} B_{1} \neq 0, C_{2} B_{2} \neq 0$. Then the corresponding two sliding modes are

$$
\dot{x}_{1}(t)=\left(A_{1}+B_{1} G_{1}\right) x_{1}(t)+D_{1} w_{1}(t)
$$




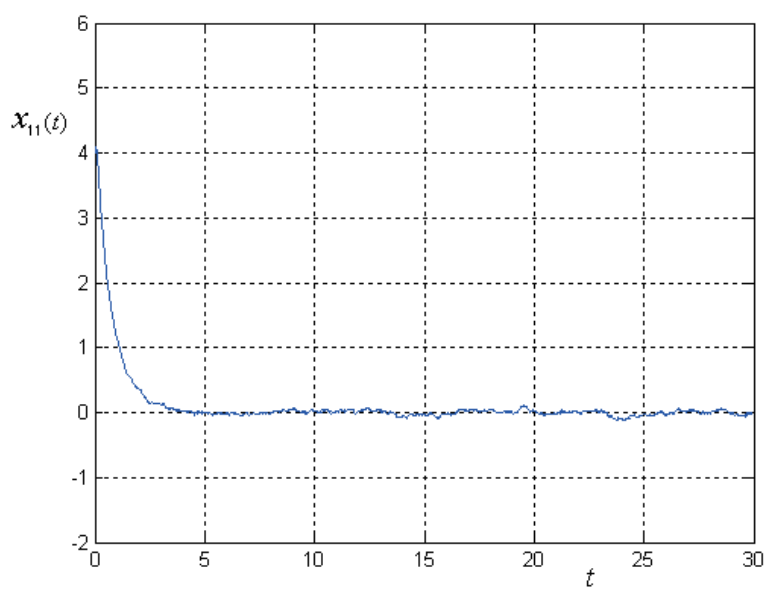

Fig. 2. Time response of state $x_{11}(t)$.

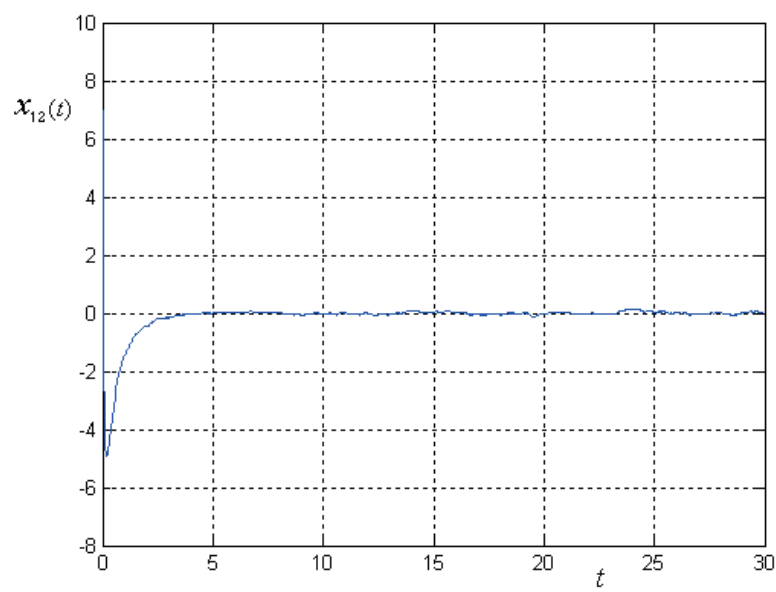

Fig. 3. Time response of state $x_{12}(t)$.

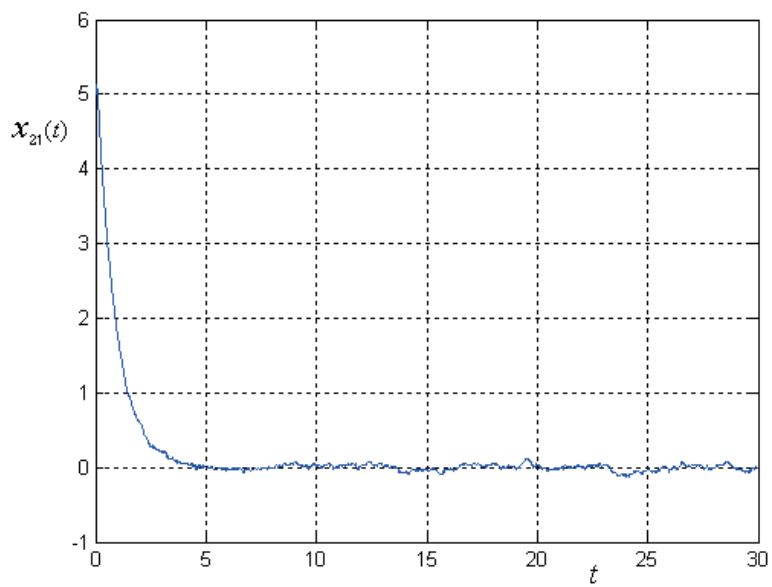

Fig. 4. Time response of state $x_{21}(t)$.

$$
y_{1}(t)=F_{1} x_{1}(t)
$$

and

$$
\begin{aligned}
& \dot{x}_{2}(t)=\left(A_{2}+B_{2} G_{2}\right) x_{2}(t)+D_{2} w_{2}(t) \\
& y_{2}(t)=F_{2} x_{2}(t)
\end{aligned}
$$

$$
\text { respectively. }
$$

Step 2: Following the LMI algorithms in main theorem, we can construct a feasible solution of the local state upper

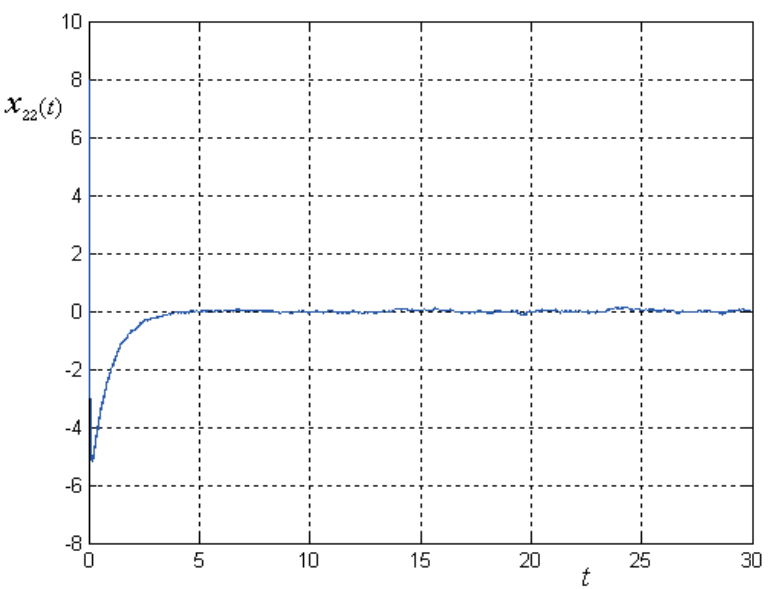

Fig. 5. Time response of state $x_{22}(t)$.

bound covariance matrices $\tilde{X}_{1}=\left[\begin{array}{cc}1.1836 & -1.5122 \\ -1.5122 & 2.7282\end{array}\right]$ and $\tilde{X}_{2}=\left[\begin{array}{cc}0.6671 & -0.7542 \\ -0.7542 & 1.7888\end{array}\right]$ in which their diagonal elements satisfy the performance constraints (58) and (59). And the related matrices are $L_{1}=\left[\begin{array}{ll}9.0473 & -31.3765\end{array}\right]$ and $L_{2}=\left[\begin{array}{ll}6.8812 & -38.1604\end{array}\right]$, respectively. Therefore, the control feedback gain matrices for each subsystem are as follows

$$
G_{1}=\left[\begin{array}{ll}
-24.1562 & -24.8901
\end{array}\right]
$$

and

$$
G_{2}=\left[\begin{array}{ll}
-26.3698 & -32.4508
\end{array}\right] .
$$

Step 3: From (13), the switching functions of two subsystems are

$$
\begin{aligned}
S_{1}(t) & =\left[\begin{array}{ll}
0 & 1
\end{array}\right] x_{1}(t)-\int_{0}^{t}\left[\begin{array}{ll}
-26.1562 & -21.8901
\end{array}\right] x_{1}(\tau) d \tau \\
& \text { and } \\
S_{2}(t) & =\left[\begin{array}{ll}
-2 & 1
\end{array}\right] x_{2}(t)-\int_{0}^{t}\left[\begin{array}{ll}
-30.3698 & -29.4508
\end{array}\right] x_{2}(\tau) d \tau .
\end{aligned}
$$

Step 4: From (19), the desired controllers of two subsystems are

$$
\begin{gathered}
u_{1}(t)=\left[\begin{array}{ll}
-24.1562 & -24.8901
\end{array}\right] x_{1}(t) \\
-\left[\begin{array}{ll}
1.42\left\|x_{2}(t)\right\|+0.6\left\|x_{1}(t)\right\|+2
\end{array}\right] \operatorname{sgn}\left(S_{1}(t)\right) \\
u_{2}(t)=\left[\begin{array}{ll}
-26.3698 & -32.4508
\end{array}\right] x_{2}(t) \\
-\left[9.5034\left\|x_{1}(t)\right\|+0.8944\left\|x_{2}(t)\right\|+2\right] \operatorname{sgn}\left(S_{2}(t)\right)
\end{gathered}
$$

where $k_{1}=1.42, k_{2}=4.25, \quad \beta_{1}=0.6, \quad \beta_{2}=0.4$ and $\alpha_{1}=\alpha_{2}=2$ are chosen.

From the above design procedure, we can conclude that the local state upper bound covariance $\tilde{X}_{i}$ will be achieved if the system is driven by the controller (66) (67). 


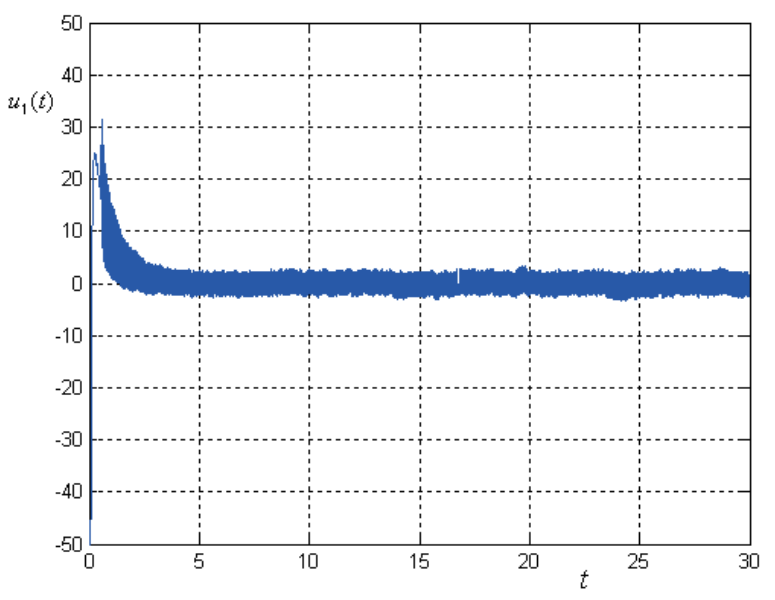

Fig. 6. Time response of state $u_{1}(t)$.

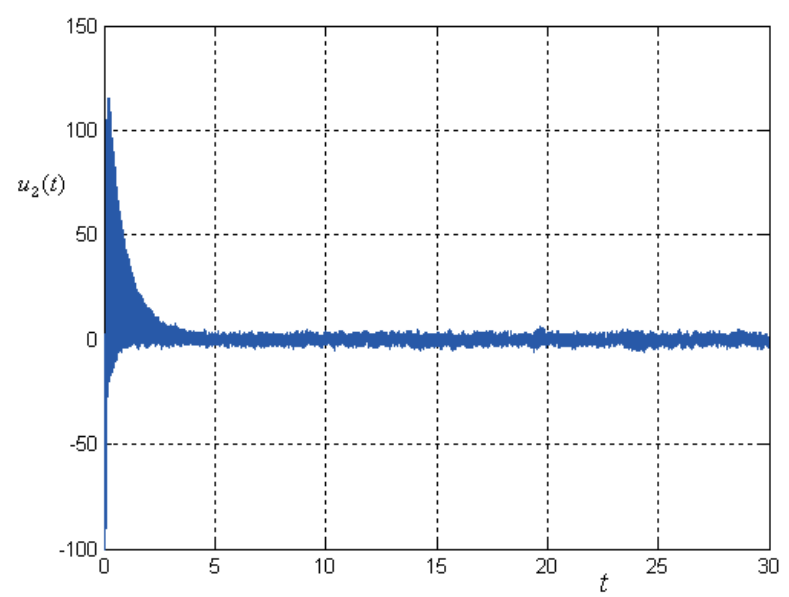

Fig. 7. Time response of state $u_{2}(t)$.

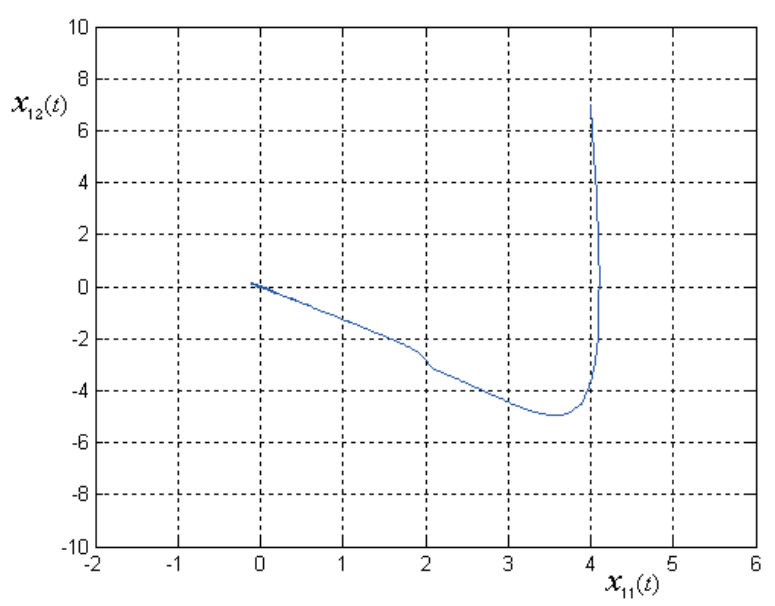

Fig. 8. The phase plane of $\left(x_{11}(t), x_{12}(t)\right)$.

The simulation result for the controlled state responses $x_{11}(t), x_{12}(t), x_{21}(t)$, and $x_{22}(t)$ are shown in Figs. 2 5, respectively. The time response of $u_{1}(t)$ and $u_{2}(t)$ are shown in Figs. 6 7, respectively. The phase plane of $\left(x_{11}(t), x_{12}(t)\right)$ and $\left(x_{21}(t), x_{22}(t)\right)$ are shown in Figs. 8 and 9, respectively. It is

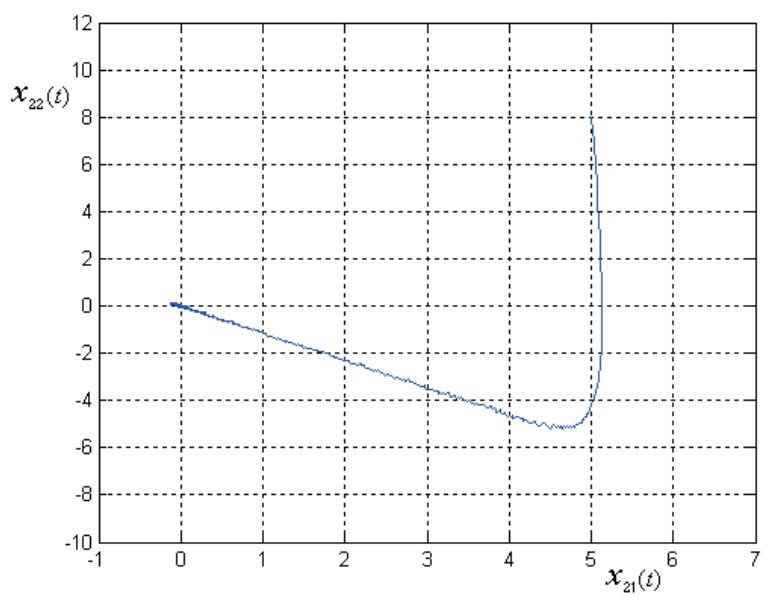

Fig. 9. The phase plane of $\left(x_{21}(t), \quad x_{22}(t)\right)$.

easy to check that the matrices $M_{\gamma_{1}}$ and $M_{\gamma_{2}}$, which were defined in Lemma 3.5, have no eigenvalues on the imaginary axis; hence the $H_{\infty}$ norm constraints (56) and (57) are satisfied. Moreover, the variances of $x_{11}(t), x_{12}(t), x_{21}(t)$, and $x_{22}(t)$ are $0.2347,0.3796,0.4254$ and 0.4886 , respectively. Therefore, the individual variance constraints (58) and (59) are also satisfied. We also check the poles of subsystem (52) and subsystem (53) locating in $-1.2684,-20.6217,-1.1549$ and -26.2959 , respectively those satisfy the pole location constraint of (54) and (55), respectively.

\section{CONCLUSIONS}

This paper has applied the invariance property of SMC to the LSUBCC such that the both uncertain interconnection terms and an unknown nonlinear function can be ignored for the large-scale systems. Since the utilization of SMC and UBCC, the control feedback gain matrix $G_{i}$ constructed by LMI approach not only achieves the multi-objective performance constraints for the closed-loop system but also determines the sliding surface of the system. Finally, a numerical example is adopted to illustrate the proposed method. The results of simulation show that the presented approach is effective in designing a multi-objective controller for the large-scale systems. In this paper, a new scheme of combination of SMC and LMI methods has been successfully demonstrated and the application of this scheme to some high performance complex systems will be developed in the future.

\section{ACKNOWLEDGEMENT}

This research was supported in part by the National Science Council of Taiwan, ROC, under the Grant NSC 93-2218-E270-003.

\section{REFERENCES}

1. Ball, J. A. and Cohen, N., "Sensitivity minimization in an $H_{\infty}$ norm: parametrization of all suboptimal solutions," International Journal of Control, Vol. 46, pp. 785-816 (1987).

2. Bernstein, D. S. and Haddad, W. M., "LQG control with an $H_{\infty}$ per- 
formance bound: a Riccati equation approach," IEEE Transaction on Automatic Control, Vol. 34, pp. 293-305 (1989).

3. Boyd, S. P. and Barratt, C. H., Linear Controller Design, Limits of Performance, Prentice-Hall, Inc., New Jersey (1991).

4. Boyd, S. P., Ghaoui, L. El., Feron, E. and Balakrishnan, V., Linear Matrix Inequalities in Systems and Control Theory, SIAM, Philadelphia (1994).

5. Chang, K. Y. and Wang, W. J., "Local state covariance assignment for stochastic large-scale systems," ASME Journal of Dynamic Systems, Measurement, and Control, Vol. 121, No. 1, pp.139-142 (1999).

6. Chang, K. Y. and Wang, W. J., " $H_{\infty}$ norm constraint and variance control for stochastic uncertain large-scale systems via sliding mode concept," IEEE Transactions on Circuits and Systems -I Fundamental Theory and Applications, Vol. 46, No. 18, pp. 1275-1280 (1999).

7. Chang, K. Y. and Chang, W. J., "Variable structure controller design with $H_{\infty}$ norm and variance constraints for stochastic model reference systems," IEE Proceedings, Part D, Control Theory and Applications, Vol. 146, No.6, pp.511-516 (1999).

8. Chang W. J. and Chang, K. Y., " $\mathrm{H}_{\infty}$ norm and variance constrained controller design for perturbed stochastic systems via variable structure control," Journal of Marine Science and Technology, Vol. 7, No. 1, pp. 26-34 (1999).

9. Chang, W. J. and Chang, K. Y., "Multivariable performance constrained sliding mode control for ship yaw-motion systems with perturbations," International Journal of Adaptive Control and Signal Processing, Vol. 14, No. 4, pp.393-405 (2000).

10. Chang, W. J. and Chung, H. Y., "Upper bound covariance control of discrete perturbed systems," Systems \& Control Letters, Vol. 19, No.14, pp. 493-498 (1992).

11. Chilali, M. and Gahinet, P., " $H_{\infty}$ design with pole placement constraints: an LMI approach," IEEE Transaction on Automatic Control, Vol. 41, No. 3, pp. 358-367 (1996).

12. Chilali, M., Gahinet, P. and Apkarian, P., "Robust pole placement in LMI regions," IEEE Transaction on Automatic Control, Vol. 44, No. 20, pp. 2257-2270 (1999).

13. Chung, H. Y. and Chang, W. J., "Covariance control with variance constraints for continuous perturbed stochastic systems," System \& Control Letters, Vol. 19, No.13, pp. 413-417 (1992).

14. Chung, H. Y. and Chang, W. J., "Constrained variance design for bilinear stochastic continuous systems," IEE Proceedings, Part D, Control Theory and Applications, Vol. 138, No. 2, pp. 145-150 (1991).

15. Drazenovic, B., "The invariance conditions in variable structure systems," Automatica, Vol. 5, pp. 287-295 (1969).

16. Francis, B. A. and Doyle, J. C., "Linear control theory with an $H_{\infty}$ optimality criterion," SIAM Journal on Control Optimization, Vol. 25, pp. 815-844 (1987).

17. Francis, B. A., A Course in $H_{\infty}$ Control Theory, Springer-Verlag, New York (1987).

18. Furuta, K. and Kim, S. B., "Pole assignment in a specified disk," IEEE Transaction on Automatic Control, Vol. 32, No. 13, pp. 423-427 (1987).

19. Hotz, A. and Skeleton, R. E., "Covariance control theory," Int. J. Control,
Vol. 46, No. 1, pp. 13-32 (1987).

20. Hung, J. Y., Gao, W. B. and Hung, J. C., "Variable structure control: a survey," IEEE Trans. Industrial Electronics, Vol. 40, pp. 2-22 (1993).

21. Haddad, W. M. and Bernstein, D. S., "Controller design with regional pole constraints," IEEE Transaction on Automatic Control, Vol. 37, No. 1, pp. 54-69 (1992).

22. Khurana, H. S., Ahson, I. and Lamba, S. S., "On stabilization of large-scale control systems using variable structure systems theory," IEEE Trans. Automatic Control, Vol. 31, pp. 176-178 (1986).

23. Kawasaki, N. and Shimemura, E., "Determining quadratic weighting matrices to locate poles in a specified region," Automatica, Vol. 19, No. 13 , pp. 557-560 (1983).

24. Lee, J. L. and Wang, W. J., "Robust decentralized stabilization via sliding mode control," Control-Theory and Advanced Technology, Vol. 9, No. 3, pp. 721-732 (1993).

25. Niu, Y., Ho, D. W C, Lam, J., "Robust integral sliding mode control for uncertain stochastic systems with time-varying delay," Automatica, Vol. 41, pp. 873-880 (2005).

26. Oksendal, B., Stochastic Differential Equations: An introduction with applications, Springer, New York (1985).

27. Sundareshan, M. K. and Elbanna, R. M., "A constructive procedure for stabilization of large-scale system by informationally decentralized controllers," IEEE Transactions on Automatic Control, Vol. 36, No. 15, pp. 848-852 (1991).

28. Utkin, V. I., "Variable structure control systems with sliding modes," IEEE Trans. Automatic Control, Vol. 22, pp. 212-222 (1997).

29. Veillette, R. J. and Medanic, J. V., " $H_{\infty}$-norm bounds for ARE-based designs," Systems \& Control Letters, Vol. 13, pp. 193-204 (1989).

30. Wang, W. J. and Chang, K. Y., "Variable structure based covariance assignment for stochastic multivariable model reference systems," Automatica, Vol. 36, pp. 141-146 (2000).

31. Xu, X., Wu, Y. and Huang, W., "Variable structure control approach of decentralized model-reference adaptive systems," IEE Proc. Part D. Control Theory and Applications, Vol. 137, pp. 302-306 (1990).

32. Xu, J. H., Skelton, R. E. and Zhu, G., "Upper and lower covariance bounds for perturbed linear systems," IEEE Transactions on Automatic Control, Vol. 35, No. 16, pp. 944-948 (1990).

33. Yaz, E. and Skelton, R. E., "Robust regional pole assignment with output feedback," Proceeding of the 32nd Conference on Decision and Control (1993).

34. Yeh, H. H., Banda, S. S., Heise, S. A. and Bartlett, A. C., "Robust control design with real-parameter uncertainty and unmodeled dynamics," Journal of Guidance, Control, and Dynamics, Vol. 13, No. 14, pp. $1117-1125$ (1990).

35. Yeung, K. S. and Chen, Y. P., "A new controller design for manipulators using the theory of variable structure systems," IEEE Transaction on Automatic Control, Vol. 33, No. 2, pp. 200-206 (1988).

36. Zames, G., "Feedback and optimal sensitivity: model reference transformations, multiplicative seminorm and approximate inverse," IEEE Transaction on Automatic Control, Vol. 26, pp. 301-320 (1981). 